\title{
Scenario of Poisoning Cases in Adults Admitted in Manipal Teaching Hospital, Pokhara, Nepal
}

\author{
Maskey $A,{ }^{1^{*}}$ Parajuli M, ${ }^{1}$ Kohli SC, ${ }^{1}$ Baral $S,{ }^{1}$ Basnet $S,{ }^{2}$ Poudel $N^{1}$ \\ ${ }^{1}$ Department of Medicine, ${ }^{2}$ Department of Pediatrics, Manipal Teaching Hospital, Pokhara, Nepal
}

\section{* Corresponding Author: \\ Dr. Abhishek Maskey, MBBS, MD \\ Manipal Teaching hospital, Pokhara, Nepal. \\ Email: maskey21@hotmail.com}

\section{Citation}

Maskey A, Parajuli M, Kohli SC, Baral S, Basnet S, Poudel $N$. Scenario of poisoning cases in adults admitted in Manipal Teaching Hospital, Pokhara, Nepal. Nepal Journal of Medical Sciences. 2012; 1(1): 23-26.

\begin{abstract}
Background: Acute poisoning is a common medical emergency encountered in practice. The knowledge profile of poisoning cases encountered in a particular area is useful to prepare health care professionals to handle these emergencies efficiently.
\end{abstract}

Methods: This retrospective study was carried out by perusing and analyzing the hospital records of all the 160 cases of poisoning admitted above 15 years of age to Manipal Teaching Hospital, Pokhara, Nepal from July 2008 to June 2011.

Results: The maximum percentage (43.1\%) of poisoning cases occurred in younger age group (15-24 years). Gender distribution of poisoning cases showed steep rise in males after 40 years of age with male to female ratio of 3.8:1. Suicidal poisoning are most common 122 (76\%). Organophosphorus compounds were most common cause of poisoning $67(41.9 \%)$.

Conclusion: Highest number of cases of poisoning was encountered in younger age group 15-24 years. There was steep rise of poisoning cases after 40 years of age in males ( $\mathrm{M}: \mathrm{F}=3.8: 1)$. Organophosphorus compounds were most commonly used for this purpose.

Keywords: Acute poisoning; organophosphorus; snake bite; suicide

\section{Background:}

Acute poisoning is a medical emergency. Poisoning is a common means in both completed and attempted suicide. It was responsible for around 600,000 deaths in 1990 in the developing world. ${ }^{1}$ Due to easy availability and its low cost; pesticides, rodenticides, chemicals and various drugs are used mainly for suicidal poisoning in developing countries. Drug abuse, overdose and accidental ingestion may be the other cause.

There are only limited studies conducted in western Nepal in this subject. In view of above, this study has been undertaken to analyze various aspects of poisoning cases including age, gender distribution, background of poison ingestion, nature of poison used, clinical presentation and outcome.

Poison is substance capable of producing damage or dysfunction in the body by its chemical activity. It can enter the body by various routes to produce local and systemic effects. Poisoning is a qualitative term used to define the potential of a chemical substance in acting adversely or deleteriously on the body. ${ }^{2}$ It is important to know the nature and severity of poisoning in order to take prompt appropriate treatment to save life and reduce morbidity and mortality. 
Methods:

This is a retrospective hospital record based study conducted in tertiary care hospital in Pokhara. The study included 160 cases of various acute poisoning due to drugs and chemicals in people above 15 years of age in the year July 2008 to June 2011. Cases of snake bite were also included in this study. Cases with food poisoning and allergic reaction to drugs were not included in the study. Data regarding age, sex, referral, circumstance of poisoning, name of poisonous substance, chemical type, and duration of hospitalization, severity and outcome were collected in pre-structured Proforma.

Circumstantial evidence such as empty bottles and tablets were also collected for general physical examination and systemic examination of patients. The data collected was entered in computer data base and analysis was done by using SPSS 16.

\section{Results:}

Out of total 160 cases of poisoning under study, 90 (56.2\%) were males while $70(43.8 \%)$ were females. Out of total 160 cases, 69 cases $(43.1 \%)$ were seen in younger age group (15-24 years). There was no significant gender difference in occurrence of poisoning cases up to 40 years of age. However after 40 years there was steep rise of poisoning cases in males with male to female ratio rising to $3.8: 1$

The majority of poisoning cases $67(41.9 \%)$ were due to organophosphorus compounds followed by rodenticides and snake bite. Drug overdose as a case of poisoning was seen in $1.6 \%$ of cases only. Drugs used were morphine, benzodiazepine, carbamazepine, antipsychotic drugs and mixture of tablets.

Overall hospital mortality in poisoning cases was $11(6.8 \%)$ while 31 cases $(19.4 \%)$ cases were taken home against medical advice in critical condition due to logistic reasons and financial constraints. The causes of death in 8 cases of organophosphorus compounds were respiratory arrest ( 5 cases), pneumonia and septicemia ( 2 cases) and sudden cardiac arrest in ( 1 case).

Out of 160 cases, $20(8 \%)$ of cases had history of neuropsychiatric illness. Among them, 13 (65\%) were suffering from depression and 4 (20\%) of them had history of previous unsuccessful suicidal attempt. Study background of poisoning showed that in $122(76.2 \%)$ cases, poison were consumed with suicidal intent. In others it was mainly accidental. Homicidal poisoning was seen only in one case. The most common agent used was for suicidal cases were organophosphorus $60(49.1 \%)$ followed by $22(13.7 \%)$ rodenticides.

The symptomatology of cases varied according to substance used. A total of 105 cases (65.6\%) with nausea and vomiting were the commonest presenting complaints. Two cases of Aconite and 1 case of Oleandar poisoning presented with wide complex ventricular tachycardia. All the cases of snake bite presented with vasculotoxic features except one who was bitten by a Krait had presented with neurotoxic features.

Table 1: Types of poisoning, gender distribution and their outcomes

\begin{tabular}{|c|c|c|c|c|c|}
\hline \multirow{2}{*}{$\begin{array}{l}\text { Types of } \\
\text { poisoning }\end{array}$} & \multirow{2}{*}{$\begin{array}{l}\text { Number of } \\
\text { patients (\%) }\end{array}$} & \multicolumn{2}{|c|}{ Gender } & \multicolumn{2}{|c|}{ Outcome } \\
\hline & & Male & Female & Improved & Expired \\
\hline Organophosphorus & 67 (41.9) & 37 & 30 & 59 & 8 \\
\hline Rodenticide & $23(14.4)$ & 12 & 11 & 22 & 1 \\
\hline Snake bite & $16(10.0)$ & 10 & 6 & 16 & \\
\hline $\begin{array}{l}\text { Mixed (various } \\
\text { sedatives) }\end{array}$ & $12(7.5)$ & 6 & 6 & 12 & \\
\hline Unknown & $11(6.9)$ & 6 & 5 & 11 & \\
\hline Drugs & $10(6.2)$ & 6 & 4 & 10 & \\
\hline Cypermethrin & $6(3.7)$ & 3 & 3 & 4 & 2 \\
\hline Paracetamol & $5(3.1)$ & 3 & 2 & 5 & \\
\hline Acid & $3(1.9)$ & 2 & 1 & 3 & \\
\hline Aconite & $2(1.2)$ & 2 & 0 & 2 & \\
\hline Dhatura & $2(1.2)$ & 1 & 1 & 2 & \\
\hline Mushroom & $2(1.2)$ & 1 & 1 & 2 & \\
\hline Oleander & $1(0.6)$ & 1 & 0 & 1 & \\
\hline Total & 160 & 90 & 70 & 149 & 11 \\
\hline
\end{tabular}

Table 2: Types of disposal of patient

\begin{tabular}{lcc}
\hline Disposal & $\begin{array}{c}\text { Number } \\
\text { of cases }\end{array}$ & $\begin{array}{c}\text { Percentage } \\
(\%)\end{array}$ \\
\hline Discharge after management & 118 & 73.7 \\
LAMA* & 31 & 19.4 \\
Died at hospital & 11 & 6.9 \\
Total & 160 & 100 \\
\hline
\end{tabular}

*LAMA: Left against medical advice

Table 3: Common presentation of Poisoning

\begin{tabular}{lcc}
\hline Clinical features & No. of patients & Percentage (\%) \\
\hline Nausea and vomiting & 105 & 65.6 \\
Disorientation & 47 & 29.4 \\
Pain abdomen & 31 & 19.4 \\
Cardiac arrhythmia & 3 & 1.9 \\
\hline
\end{tabular}


Table 4: Medical conditions record

\begin{tabular}{lcc}
\hline $\begin{array}{c}\text { Previous history of } \\
\text { Neuropsychiatric Illness }\end{array}$ & $\begin{array}{c}\text { Number of } \\
\text { patients }\end{array}$ & $\begin{array}{c}\text { Percentage } \\
(\%)\end{array}$ \\
\hline Depression & 13 & 65 \\
Paranoid Schizophrenia & 2 & 10 \\
Anxiety disorder & 2 & 10 \\
Bipolar disorder & 1 & 5 \\
Obsessive compulsive disorder & 1 & 5 \\
Psychosis & 1 & 5 \\
Total & 20 & 100 \\
\hline
\end{tabular}

Discussion:

The study involved 160 patients. Acute poisoning cases accounted for around $1 \%$ of total cases admitted in medicine department from July 2008 to June 2011. Our study showed that highest number of patients $69(43.1 \%)$ belonged to age group 15-24 years. This is in agreement with the findings of two other studies in Nepal where maximum number of cases of poisoning were seen in age group 16-25 years ${ }^{3}$ and 20-30 years. ${ }^{4}$ Similar findings was reported in series from Turkey. ${ }^{5}$

Various studies had reported very high female preponderance. In a study reported at Bir hospital by Bajracharya et $\mathrm{al},{ }^{4}$ almost three fourth of the cases were females. Where as in his study, Paudyal $\mathrm{BP}^{6}$ also found female preponderance. In another study carried in Turkey $59.5 \%$ of cases were females and $40.5 \%$ males. $^{7}$ Many other previous studies from Nepal have also reported female preponderance of poisoning cases. $^{8-10}$ In contrast to their study, our study showed a male preponderance of poisoning cases $(56.2 \%$ males compared to $43.8 \%$ females). Ghimere et al, in their comparison of data of poisoning of year 1990-1992 and 2000-2002 also noticed significant increase in percentage of male poisoning cases from $31.4 \%$ to $42.7 \% .{ }^{11}$ Similar study done in Dharan showed male cases were more than females. ${ }^{12}$

In present study, the most commonly ingested poison was organophosphorus compound (41.9\%) followed by rodenticide $(17.4 \%)$. In a study reported from Patan hospital of Nepal by Paudyal et al, ${ }^{6}$ most common poison used were organophosphorus compounds $(42 \%)$ while rodenticides were responsible for $6.5 \%$ of cases of all poisoning. Poisoning due to organophosphorus compounds has been in news from Indian state of Andhra Pradesh. ${ }^{13}$ It appears that easy availability of organophosphorus compound in Nepal and India probably makes it a favorite substance for suicidal purpose.

Majority of patients (76.2\%) consumed poison with suicidal intent as compared with $37(23.1 \%)$ of the patient exposed accidentally. Findings are consistent with study done at Southern India where $78 \%$ cases were suicidal attempt and $22 \%$ were accidental. ${ }^{13}$ A study conducted in Kathmandu reported that $97 \%$ of poisoning cases admitted to hospital were due to suicidal attempt. ${ }^{14}$ A study conducted in New Delhi, India showed that $47 \%$ of their poisoning cases were due to accidental poison. Since pediatric cases were also included in their study, their findings are not comparable. ${ }^{15}$

In this study, nearly half of cases of intentional poisoning were due to organophosphorous compounds (49.2\%) followed by rodenticide (18\%). A study conducted at different central zonal and district hospital of Nepal also showed similar results where organophosphorus (40\%) was most common agent used for intentional poisoning followed by rodenticides $(15 \%) .{ }^{16}$ Similar findings were seen in a study carried out at Bir hospital by Bajracharya et al. ${ }^{4}$

The overall mortality was found to be $11(6.9 \%)$ in our study. Similar lower incidence of mortality was seen in other studies done in other countries. Study conducted by Thomas et $\mathrm{al}^{17}$ in South India showed low mortality rate of $3.3 \%$ ( 52 deaths out of 1584 cases) and other study done in Malaysia ${ }^{18}$ showed mortality rate of $3.5 \%$ (779 deaths out of 21714 cases). However, the exact rate of mortality could not be ascertained because 31 (19.4\%) of cases were taken home against medical advice due either to anticipated poor outcome or due to financial and logistic reasons.

It was seen from our study on psychiatry assessment of all suicidal attempt cases, that majority of cases were associated with acute stress reaction. Various stress in financial, academic and social factors contributed in taking of poison. In our study 20 patients had psychiatric illness among which $13(65 \%)$ had depression.

\section{Conclusion:}

Our study showed that male poisoning cases are increasing. Younger age group is more vulnerable for poisoning. Organophosphorus remains the commonest agent used for poisoning. Community based awareness programs will help to prevent the instances of poisoning. Peoples should be more informed of the dangers posed by poison. Strict rules regarding sale of pesticide which are easily accessible and affordable must be implemented. Training of physicians in the accurate diagnosis and prompt management of poisoned victims would improve the rate of survival. A widespread campaign to inform people of the possible dangers of posion would be useful. 
Original Article | Maskey A, et al. Scenario of adult poisoning in Nepal.

\section{References:}

1. Eddleston M. Patterns and problems of deliberate self poisoning in developing world. Q J Med 2000;93:715-31.

2. Linden $\mathrm{CH}$, Burns MJ, Mycyk MB. Poisoning, drug overdose and envenomation. In: Fauci AS, ed. Harrison's Principles of Internal Medicine. Volume 2. $17^{\text {th }}$ ed. New York: McGraw-Hill;2008:2741-8.

3. Ghimire RH, Sharma SP, Pandey KR, et al. A retrospective study of the changing trends of Acute Poisoning cases at Tribhuvan University Teaching Hospital, Nepal between 1990-1992 and 2000-2002. JNHRC 2003;1:38-41.

4. Bajracharya MR, Manandhar K, Deo KK, et al. Age and gender distribution in deliberate self poisoning Cases. PMJN 2008;8:44-9.

5. Guloglu C, Kara I. Acute poisoning cases admitted to a university hospital emergency department in Diyarbakir, Turkey. Hum Exp Toxicol 2005;24:49-54.

6. Paudyal BP. Poisoning: pattern and profile of admitted cases in hospital in central Nepal. J Nep Med Assoc 2005;44:92-6.

7. Yurumez Y, Durukan P, Yavuz P, et al. Acute organophosphate poisoning in university hospital emergency room patient. Intern Med 2007; 46: 965-9.

8. Pokhrel N, Gurung CK. A study of poison cases recorded in Bir hospital over four years. J Inst Med 1987;9:29-34

9. Kafle KK. Poisoning cases at T.U. Teaching hospital. J Inst Med 1989;11:297-301.

10. Rauniyar GP. Retrospective Analysis of profile of acute poisoning case in a tertiary care hospital in eastern Nepal: A four year data base from 1994 to1997. J Nep Med Assoc 1999;38:23-8.
11. Ghimere RH, Pathak UN, Sharma SP, et al. Retrospective study of poisoning cases admitted in Nepal Medical College Teaching Hospital. Nep Med Col J 2001;3:101-5.

12. Gupta SK, Joshi MP. Pesticide poisoning cases attending five major hospital of Nepal. J Nep Med Assoc 2001;41:447-56.

13. Ramesha KN, Krishnamurthy BH, Ganesh SK, et al. Pattern and outcome of acute poisoning cases in tertiary care hospital in Karnataka, India. Indian Journal of Critical Care Medicine 2009;13:152-5.

14. Singh DP, Acharya RP. Pattern of poisoning cases at Bir Hospital. J Inst Med 2006;28:3-6.

15. Srivastava A, Peshin SS, Kaleekal T, et al. An epidemiological study of poisoning cases reported to the National Poisons Information Center, All India Institute of Medical sciences, New Delhi. Hum Exp Toxicol 2005; 24:279-85.

16. Pokhrel D, Pant S, Pradhan A, et al. A comparative retrospective study of poisoning cases in central, zonal and district hospital. KUJ Sci, Eng and Tech 2008; 1:40-8.

17. Thomas M, Anandan S, Kuruvilla PJ, et al. Profile of hospital admissions following acute poisoning experiences from a major teaching hospital in South India. Adverse Drug Toxicol Rev 2000;19:313-7.

18. Rajasuriya R, Awang R, Hashim SB, et al. Profile of poisoning admissions in Malaysia. Hum Exp Toxicol 2007;26:73-8 